\title{
Evolución de la configuración microespacial de los servicios de consumo duradero en la zona metropolitana de la Ciudad de México, 1993-2013 Evolution of microspatial configuration of consumer durable services in the Mexico City metropolitan zone, 1993-2013
}

\author{
Fermín Ali Cruz Muñoz \\ http://orcid.org/0000-0001-7057-7057
}

Primera versión recibida en: 29 enero, 2020

Última versión recibida en: 28 agosto, 2020

\section{Resumen}

a organización territorial de los servicios de consumo duradero ha adquirido mayor trascendencia debido a la servicialización de la economía de las grandes metrópolis. El objetivo de este artículo es comprender la evolución de la distribución microespacial de los servicios de consumo duradero en la zona metropolitana de la Ciudad de México en el periodo de 1993 a 2013 y con ello la definición de la tendencia del patrón predominante bajo una perspectiva teórica del lugar central. La medición de la actividad económica se hizo a partir del valor agregado que ofrecieron los censos económicos a nivel de áreas geoestadísticas básicas. La distribución de este tipo de servicio ha mostrado una relativa estabilidad en la configuración policéntrica donde las vías de comunicación y distribución de la población han tenido un papel central para la localización de los nodos. Adicionalmente, se identificaron los microcambios en la actividad económica, que por su naturaleza de escala requieren de estudios más detallados para el entendimiento de los factores territoriales que los generan.

Palabras Clave: Servicios de consumo duradero, configuración espacial, Ciudad de México

1 Profesor-investigador del Centro de Investigaciones Económicas, Administrativas y Sociales del Instituto Politécnico Nacional.

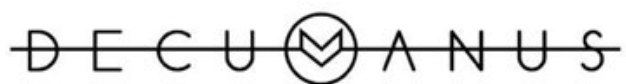

REVISTA INTERDISCIPLINARIA SOBRE ESTUDIOS URBANOS 


\section{Abstract}

The territorial organization of consumer durables services has become more important due to the tertiarization of the economy of the large metropolises. The objective of this article is to understand the evolution of the microspatial distribution of consumer durables services in the metropolitan area of Mexico City in the period 1993 to 2013 and with it the definition of the trend of the predominant pattern under a theoretical perspective of the central place. The measurement of economic activity was based on the added value offered by the economic censuses at the level of basic geostatistical areas in the study phase. The distribution of this type of service has shown a relative stability in the polycentric configuration where the communication routes and distribution of the population have played a central role for the location of the nodes. Additionally, micro-changes in economic activity were identified which, due to their scale nature, require more detailed studies to understand the territorial factors that generate them.

Keywords: Consumer durable services, spatial configuration, Mexico City

Una de las cualidades de los servicios es que en su gran mayoría son consumidos en el establecimiento donde se ofrecen. Ello tradicionalmente se expresa en una configuración intraurbana dispersa a fin de acercarse a la población. No obstante, la frecuencia con la cual se consume el servicio también influye en su estructura espacial. De tal forma que es de esperarse que los servicios cuya frecuencia de consumo sea poco frecuente, puedan agruparse para aprovechar las economías de aglomeración. Los servicios de consumo duradero se caracterizan por tener una duración de consumo más largo, como la educación o el servicio de salud, más aún cuando son altamente especializados.

A escala metropolitana se han elaborado interesantes modelos longitudinales sobre la construcción histórica de la organización espacial de la actividad urbana (Borsdorf, 2003; Janoschka, 2002; Gormsen, 1981). No obstante, poco se ha estudiado la lógica evolutiva de los servicios de consumo duradero en particular. Una indudable referencia ha sido el proceso de relocalización de la actividad económica que Dematteis y Governa (2001, p. 29) denominaron como la "explosión del centro", resultado del desarrollo de los sistemas de transporte y la expansión de las grandes urbes. Estos autores incluso argumentaron la paulatina disolución del centro hasta el punto de su desaparición. Este proceso ha tenido implicaciones importantes en la configuración de la estructura de las ciudades hacia el policentrismo o la dispersión generalizada de la actividad económica. Esto bajo un contexto de fragmentación urbana donde las grandes áreas de monouso han dado paso a micropolígonos funcionales que han mezclado actividades bajo una lógica de complementariedad. Ello ha derivado en la necesidad de la realización de estudios a una escala microespacial a fin de comprender la lógica actual de distribución metropolitana de la actividad económica, y en el caso específico de este trabajo, de los servicios de consumo duradero.

La fragmentación urbana es otro fenómeno que ha influido en la organización metropolitana de los servicios, esta puede entenderse como la descomposición

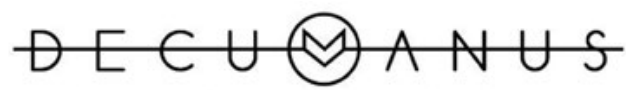

REVISTA INTERDISCIPLINARIA SOBRE ESTUDIOS URBANOS 
o seccionamiento de la estructura de las urbes (Burgess, 2011, p. 62). Este proceso se ha acompañado de una pérdida de lugares de encuentro universal, pues cada segmento de la población habita espacios excluyentes en el interior de la misma urbe (Kozak, 2011, p. 57). El seccionamiento ha generado hasta cierto grado una independencia funcional de fragmentos de la urbe, lo que refuerza el declive de la zona central, pues la población suburbana ya no requiere de viajar al centro urbano para la satisfacción de las necesidades de consumo. Los subcentros urbanos tienen la capacidad de ofrecer los servicios especializados que anteriormente se encontraban solamente en la zona central (Gaschet, 2002, p. 64).

La dispersión de los servicios tradicionalmente se ha explicado por la ubiquidad de las economías de urbanización. No obstante, han existido una serie de factores territoriales que transforman esta posible dispersión. El primero es la calidad diferenciada de la infraestructura para el caso particular de los servicios de consumo duradero y la accesibilidad física que ofrecen las vialidades y los sistemas de transporte (Méndez, 2011, p. 145). El segundo factor es la distribución heterogénea de la población con una diferenciación de poder adquisitivo. Como resultado de la segregación socioespacial de la población en el interior de las urbes, se han generado mercados diferenciados que han favorecido el incremento de la intensidad de la actividad económica en zonas específicas. Por último, la histórica centralización general del capital (Garza, 1985, p. 217) favorece que grandes empresas hayan concentrado la oferta de los servicios de consumo duradero. Esta tendencia se ha fortalecido gracias a la globalización, pues las empresas transnacionales se han posicionado en mercados locales (García, 2016, p. 149).

Tradicionalmente se retoma la teoría del lugar central como referencia para explicar la organización espacial de los servicios a una escala intraurbana (Kohsaka, 1986; Yang, 1990; Trullen y Boix, 2003; Grajales, 2006). No obstante, uno de los primeros en la aplicación de esta teoría a la escala intraurbana es Davies (1972), quien adaptó el modelo teórico con la consideración de la calidad de los servicios en función del nivel socioeconómico de la población consumidora. Ello implica la existencia de nodos de una misma jerarquía, pero con cualidades diferentes. Mientras mayor sea la jerarquía, la calidad de los servicios es más diversa, en contraste con nodos locales que concentran servicios más homogéneos en función de la población cercana. Este mercado disímil deriva en un rompimiento del sistema, donde cada fragmento urbano puede tener una estructura propia.

El objetivo de este estudio es analizar y comprender la lógica evolutiva de la organización espacial de los servicios de consumo duradero a una escala microespacial en la zona metropolitana de la Ciudad de México (ZMCM) en el periodo de 1993 a 2013. Este estudio busca ofrecer un panorama de los cambios en la localización de la actividad económica y plantear un modelo que otorgue una lógica funcional de este tipo de servicios. Para ello, el documento tiene tres partes esenciales. La primera es el diseño metodológico del análisis. La segunda parte se compone de tres secciones donde se analiza la distribución de la actividad económica en 1993, en 2013 y un estudio de los cambios en el periodo. Finalmente, se

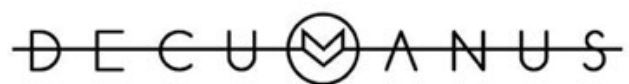

REVISTA INTERDISCIPLINARIA SOBRE ESTUDIOS URBANOS
Núm. 5. Vol. 5. Octubre 2019-Octubre 2020. Instituto de Arquitectura, Diseño y Arte.

Universidad Autónoma de Ciudad Juárez. ISSN: 2448-900X 
realiza una reflexión sobre los principales hallazgos y una propuesta de modelación a partir de la teoría del lugar central.

\section{Metodologia: análisis longitudinal de la organización territorial intraurbana}

Tradicionalmente se ha vinculado el grado de concentración o dispersión de la actividad económica a la cercanía que requiere tener el establecimiento con la demanda. En ese sentido, dicha proximidad se ha relacionado con la frecuencia de consumo de la población. Además, el tiempo de consumo no es igual para cada servicio. Garza (2008, p. 79) considera dicho factor para el establecimiento de una categorización entre el servicio de consumo inmediato y de consumo duradero. De tal suerte que los servicios de consumo duradero son toda actividad donde se ofrece un servicio que es consumido por un largo tiempo (Daniels, 1985, p. 6). ${ }^{2}$

Para determinar la organización espacial de los servicios de consumo duradero, se midió la magnitud de la producción que se realiza en el lugar. La actividad económica se define como la combinación de recursos que permiten, bajo un procedimiento o conjunto de tareas, la prestación de servicios (Instituto Nacional de Estadística y Geografía [INEGI], 1999). Lynch (1981) menciona que la actividad no solamente se limita a la acción humana, ya que en la ciudad es necesaria la consideración de las acciones de las máquinas, por lo que se requiere inclusión de todo el sistema en cuestión.

Por lo tanto, dado que el objetivo de la actividad económica es la producción de servicios, la variable que se usó para esta investigación es el valor agregado censal bruto (VACB). El INEGI (2004) la define como

el valor de la producción que se añade durante el proceso de trabajo, por la actividad creadora y de transformación del personal ocupado, el capital y la organización (factores de la producción), ejercida sobre los materiales que se consumen en la realización de la actividad económica (p. 42).

No obstante, también se incorporaron los datos relacionados con las unidades económicas y el personal ocupado, con el objetivo de calificar los establecimientos.

Las fuentes de información fueron los censos económicos de 1994 y 2014 que presentan datos de 1993 y 2013 respectivamente. De manera complementaria se consultó el Directorio Estadístico Nacional de Unidades Económicas para profundizar en las ramas y empresas que se emplazan en los nodos con trascendencia metropolitana.

La unidad geográfica de análisis fue el Área Geoestadística Básica (AGEB) urbana, se define como la unidad fundamental del Marco Geoestadístico del INEGI. Esta

2 Se retomó la metodología de Garza (2008) para la agrupación de las actividades económicas en este sector de servicios.

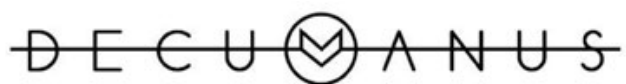

REVISTA INTERDISCIPLINARIA SOBRE ESTUDIOS URBANOS 
unidad de análisis permitió determinar, con mayor nivel de desagregación, los patrones espaciales e identificar las microdiferencias de la concentración económica.

Es claro que los límites de la ZMCM han cambiado en este lapso de tiempo. En 1993 la zona metropolitana estaba constituida por las 16 delegaciones del Distrito Federal y por 29 municipios del Estado de México (Consejo Nacional de Población [Conapo], 1994). Veinte años después estaba conformada por las 16 delegaciones del Distrito Federal, 59 municipios del Estado de México y uno del estado de $\mathrm{Hi}$ dalgo (Mapa 1) (Sedesol-Conapo-INEGI, 2012).

\section{Mapa 1. Zona metropolitana de la Ciudad de México: expansión de la zona} urbana, 1993-2013.

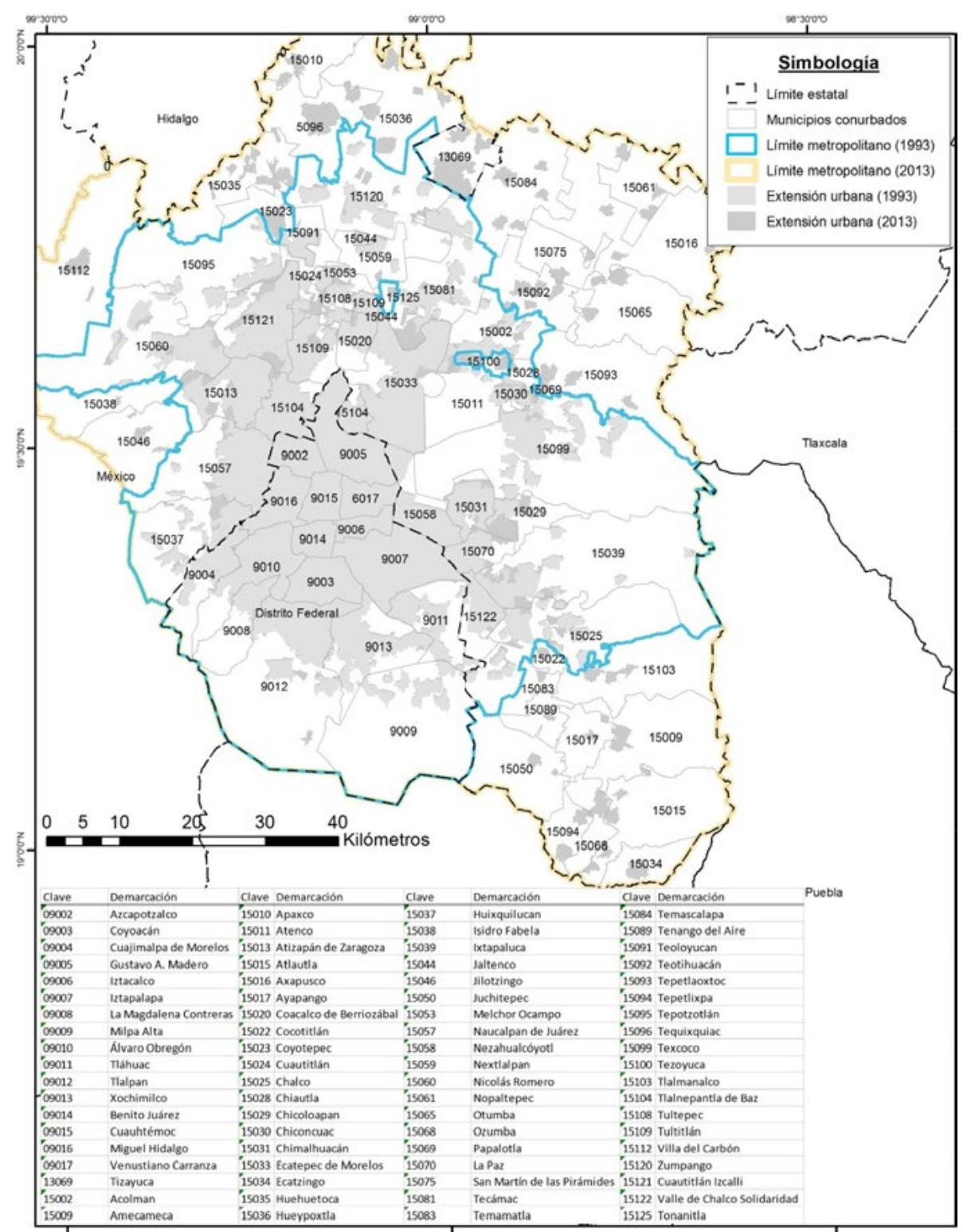

Fuente: Elaboración propia a partir del Marco Geoestadístico nacional 1995 y 2013, INEGI.

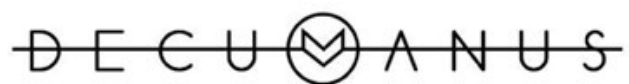

REVISTA INTERDISCIPLINARIA SOBRE ESTUDIOS URBANOS
Núm. 5. Vol. 5. Octubre 2019-Octubre 2020. Instituto de Arquitectura, Diseño y Arte.

Universidad Autónoma de Ciudad Juárez. ISSN: 2448-900X 
Para la elaboración de la comparación espacio-temporal de la actividad económica, se realizó la construcción de un sistema de información geográfica y así se definieron las AGEB que modificaron su geometría. La gran mayoría de los casos fueron áreas que se subdividieron, por lo que los datos del VACB del Censo EConómico 1994 (INEGI, 1994) del área en cuestión se repartieron en proporción a las nuevas áreas creadas por dicha partición.

Para el análisis espacial, se utilizó el índice de Hoover que cuantifica el grado de concentración en el espacio. La ventaja frente a otros índices es que puede ser ponderado por la superficie de la unidad espacial de análisis (Isard, 1960). Esta cualidad es muy conveniente para el caso de estudio debido a que las AGEB que constituyen la ZMCM son muy heterogéneas. Para estimar el índice de Hoover se utiliza la siguiente ecuación:

$$
I H=\frac{1}{2}\left|\sum \frac{P I B_{i a}}{P I B_{i t}}-\frac{A_{a}}{A_{t}}\right|
$$

Donde IH es el indice de Hoover, $P I B_{i a}$ es la producción del sector $i$ del AGEB $a$, $P I B_{i t}$ es la producción del sector $i$ en toda el área metropolitana, $A_{a}$ es el área del AGEB y $A_{t}$ es el área total de la zona metropolitana.

El rango del índice va de uno a cero, y determina el grado de concentración, por lo que se consideró para este análisis un resultado de 0 a 0.25 como una organización muy dispersa, de 0.251 a 0.50 como una distribución moderadamente dispersa, de 0.51 a 0.75 como una configuración moderadamente concentrada y de 0.751 a 1.00 como una localización muy concentrada.

Para el análisis longitudinal, se utilizó la técnica de "Cambio y participación" también conocido como Shift \& Share y se calcula de la siguiente manera:

(2) $X_{i j} g_{i j}=X_{i j} G+X_{i j}\left(G_{i}+G\right)+X_{i j}\left(g_{i j}-G_{i}\right)$

Donde $\quad X_{i j}$ representa la producción del sector i en el AGEB $j$ en 1993;

$g_{i j}$ es la tasa de crecimiento media anual de la producción en el sector $i$ en el AGEB $j$ de 1993 a 2013;

$G_{i}$ representa la tasa metropolitana de crecimiento media anual de la producción en el sector i de 1993 a 2013 y

$G$ es la tasa metropolitana de crecimiento media anual de la actividad terciaria de 1993 a 2013 (Ramajo y Márquez, 2008).

Esta técnica permite la discriminación del efecto local sobre el metropolitano y sectorial a fin de conocer los cambios resultantes de las condiciones particulares de cada unidad espacial. El dato que se analiza es el cambio local definido por

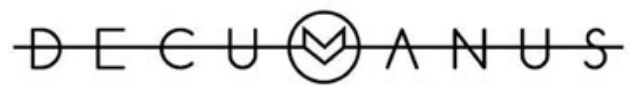

REVISTA INTERDISCIPLINARIA SOBRE ESTUDIOS URBANOS 
el último sumando cuyo valor positivo indica un efecto de atracción y un valor negativo significa expulsión.

\section{Distribución territorial en la transición de siglo}

A partir del índice de Hoover, se puede observar un proceso general hacia la concentración de los servicios de consumo duradero. En 1993 el índice estuvo en el umbral de la concentración media a alta de 0.75 . Con el paso de 20 años, se identifica un incremento a 0.81 , lo que destaca ante una tendencia generalizada hacia la dispersión de la actividad económica (Arellano y Roca, 2010).

Esta transformación se observa a partir del análisis más detallado que se presenta en el Cuadro 1. En lo que se refiere al comportamiento en 1993, destaca que $35.34 \%$ del valor agregado de toda la zona urbana en este tipo de servicio se concentra en áreas con un nivel de producción muy alto y apenas ocupan $1.13 \%$ de la superficie metropolitana. En contraste, $44.83 \%$ de la superficie de la metrópoli no registra actividad alguna, lo que también contribuye a la concentración de esta actividad económica. Por último, al conjuntar las AGEB con producción superior a la media, se encontró que aportan $61.41 \%$ del valor agregado y ocupan solamente $3.82 \%$ de la superficie urbana.

\begin{tabular}{|c|c|c|c|c|c|c|c|c|c|c|c|c|}
\hline \multirow{2}{*}{$\begin{array}{l}\text { Nivel de } \\
\text { Producción }\end{array}$} & \multicolumn{6}{|c|}{1993} & \multicolumn{6}{|c|}{2013} \\
\hline & $\begin{array}{l}\text { Canti- } \\
\text { dad de } \\
\text { AGEB }\end{array}$ & $\%$ & Superficie $^{a}$ & $\%$ & $\begin{array}{c}\text { Valor } \\
\text { Agregado }\end{array}$ & $\%$ & $\begin{array}{l}\text { Cantidad } \\
\text { de AGEB }\end{array}$ & $\%$ & Superficie $^{a}$ & $\%$ & $\begin{array}{l}\text { Valor Agre- } \\
\text { gado }^{\mathrm{b}}\end{array}$ & $\%$ \\
\hline Total & 4738 & 100.00 & 194145 & 100.00 & 41600818 & 100.00 & 5694 & 100.00 & 229706 & 100.00 & 45399213 & 100.00 \\
\hline Muy alto & 45 & 0.95 & 2201 & 1.13 & 14701831 & 35.34 & 37 & 0.65 & 2216 & 0.96 & 16543922 & 36.44 \\
\hline Alto & 42 & 0.89 & 1737 & 0.89 & 4597039 & 11.05 & 22 & 0.39 & 833 & 0.36 & 2916612 & 6.42 \\
\hline Medio & 95 & 2.01 & 3489 & 1.80 & 6250072 & 15.02 & 77 & 1.35 & 4063 & 1.77 & 6135406 & 13.51 \\
\hline Bajo & 556 & 11.73 & 22689 & 11.69 & 10917797 & 26.24 & 727 & 12.77 & 33646 & 14.65 & 14849878 & 32.71 \\
\hline Muy Bajo & 2041 & 43.08 & 76452 & 39.38 & 5323416 & 12.80 & 3100 & 54.44 & 126364 & 55.01 & 6624146 & 14.59 \\
\hline Sin actividad & 1945 & 41.05 & 87029 & 44.83 & - & 0.00 & 1694 & 29.75 & 61030 & 26.57 & - & 0.00 \\
\hline $\begin{array}{l}\text { Sin produc- } \\
\text { ción }\end{array}$ & 14 & 0.30 & 548 & 0.28 & -189336 & -0.46 & 37 & 0.65 & 1554 & 0.68 & -1670751 & -3.68 \\
\hline
\end{tabular}

Fuente: Elaboración propia a partir de INEGI (1994; 2014).

${ }^{a}$ La superficie se expresa en hectáreas.

${ }^{b}$ El valor agregado se presenta en miles de millones de pesos constantes a 2013.

En 2013, en consecuencia del panorama de mayor concentración, el índice de Hoover muestra que las AGEB con muy alta generación de valor agregado incrementan su participación metropolitana con $36.44 \%$ en una superficie que solamente representa $0.96 \%$ de la metrópoli. No obstante, las áreas sin producción de servicios de consumo duradero se reducen a $26.57 \%$ de la superficie urbana, lo que favorece a la proporción de participaciones de las áreas con baja y muy baja producción. De tal manera que la mayoría del territorio, el 55.01\%, registra

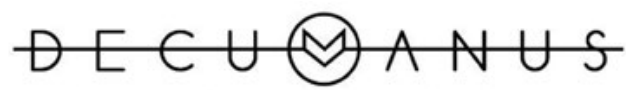

REVISTA INTERDISCIPLINARIA SOBRE ESTUDIOS URBANOS 
una producción muy baja y aporta solamente $14.59 \%$ del valor agregado. En contraparte, las AGEB por encima de la media de producción metropolitana aportan $56.37 \%$ del valor agregado y ocupan apenas 3.09\% de la superficie de la metrópoli (Cuadro 1).

Es clara la tendencia hacia la concentración que muestra este tipo de servicios en el periodo de los 20 años considerados. Este proceso puede estar vinculado con las ventajas externas que ofrece la aglomeración o puede ser resultado de la centralización general del capital de determinadas empresas que agrupan una importante proporción de la actividad. Fue necesaria la revisión de la localización de las zonas con alta actividad a fin de profundizar en la estructura intrametropolitana de los servicios de consumo duradero y así definir su evolución territorial en el plazo de análisis.

\section{Organización multinodal en la última década del siglo XX}

Los servicios de consumo duradero han mostrado una centralización territorial en la ZMCM al principio de la última década del siglo XX. Esta concentración en la zona central de la metrópoli es acompañada por una mayor presencia de nodos en el lado poniente como resultado del poder adquisitivo de la población de dicha zona (Mapa 2). ${ }^{3}$ De tal manera que en el poniente de la urbe se encuentran la totalidad de las AGEB con producción muy alta y prácticamente la totalidad de las AGEB con alta generación del valor agregado.

De manera más detallada, se observa la conformación de 10 nodos de servicios de consumo duradero. Estas concentraciones están constituidas por al menos un AGEB de muy alta producción, contigua a otras con un nivel superior a la media, agrupan $45.5 \%$ de la producción metropolitana en una superficie de solamente 2.5\% del área urbana (Cuadro 2). En estas concentraciones es claramente mayor la intensidad de la producción, pues rebasa casi 20 veces la producción media metropolitana. Es decir, los nodos promedian una intensidad de producción de \$3.8 millones de pesos por hectárea, en contraste con los \$200 mil pesos por hectárea de la metrópoli.

3 Se retoma el estudio de Aguilar y Mateos (2011) para identificar la distribución de la población en función de sus características socioeconómicas en el interior de la zona metropolitana.

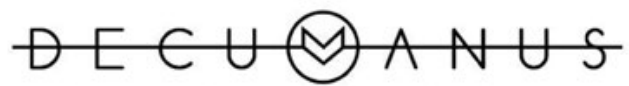

REVISTA INTERDISCIPLINARIA SOBRE ESTUDIOS URBANOS 
Mapa 2. Zona metropolitana de la Ciudad de México: distribución territorial de servicios de consumo duradero, 1993.

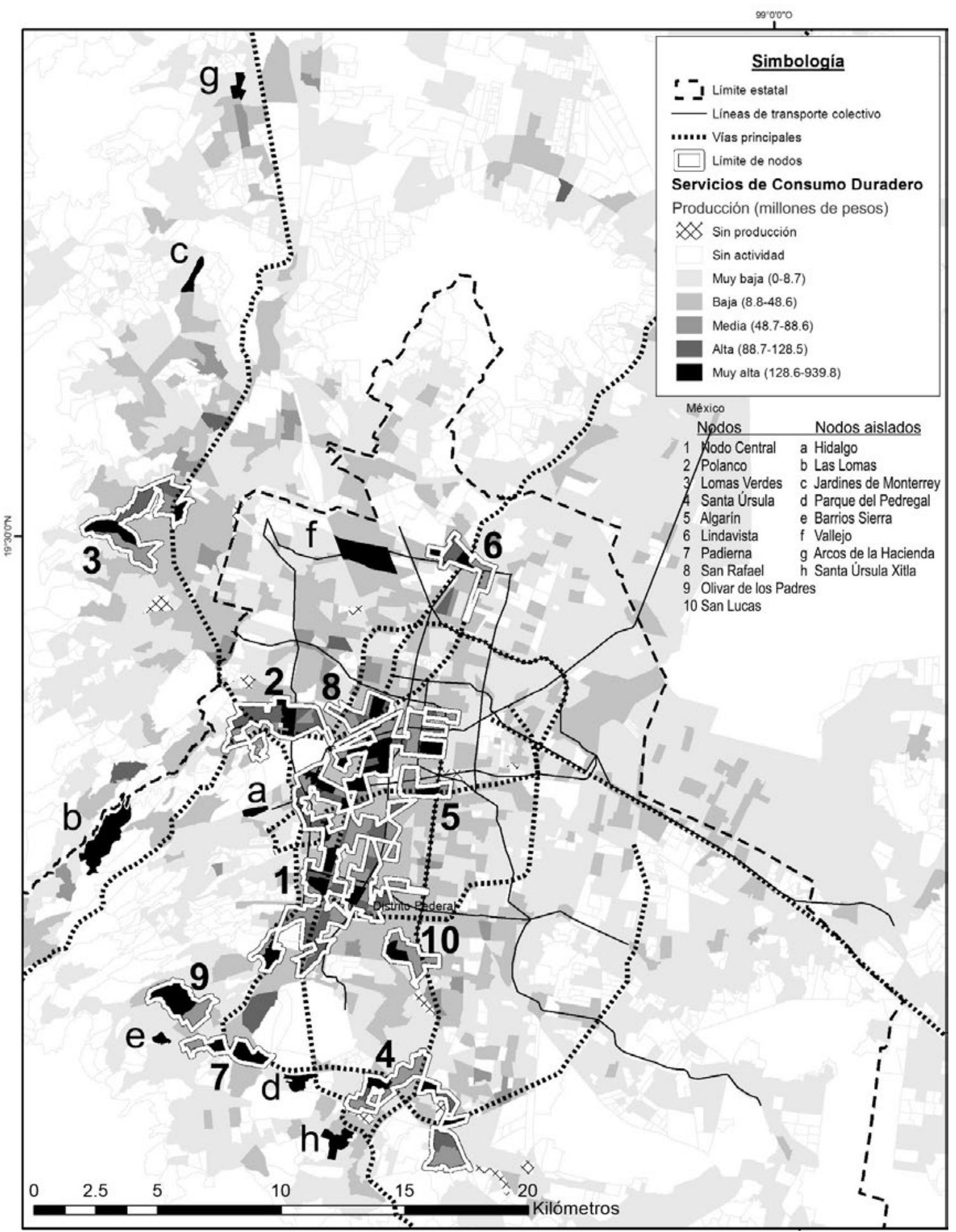

Fuente: Elaboración propia a partir de INEGI (1994).

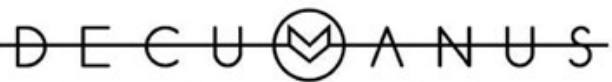

REVISTA INTERDISCIPLINARIA SOBRE ESTUDIOS URBANOS 
Cuadro 2. Zona metropolitana de la Ciudad de México: características generales de los agrupamientos de servicios de consumo duradero, 1993.

\begin{tabular}{|c|c|c|c|c|c|c|}
\hline \multirow{2}{*}{ Agrupamientos } & \multicolumn{3}{|c|}{ Valor agregado ${ }^{a}$} & \multirow{2}{*}{$\begin{array}{l}\text { Área } \\
\%\end{array}$} & \multirow{2}{*}{$\begin{array}{l}\text { Intensidad de } \\
\text { producción }\end{array}$} & \multirow{2}{*}{$\begin{array}{c}\text { Personal por } \\
\text { establecimiento }\end{array}$} \\
\hline & Hectáreas & $\%$ & Hectáreas & & & \\
\hline Total de Actividad & 41601 & 100.0 & 194145 & 100.00 & 0.2 & 3.8 \\
\hline Total de nodos & 18936 & 45.5 & 4924 & 2.54 & 3.8 & 9.1 \\
\hline 1 Nodo central & 9797 & 23.6 & 2334 & 1.20 & 4.2 & 7.5 \\
\hline 2 Polanco & 2414 & 5.8 & 471 & 0.24 & 5.1 & 11.3 \\
\hline 3 Lomas Verdes & 1394 & 3.4 & 522 & 0.27 & 2.7 & 17.3 \\
\hline 4 Santa Úrsula & 1358 & 3.3 & 556 & 0.29 & 2.4 & 23.8 \\
\hline 5 Algarín & 1049 & 2.5 & 85 & 0.04 & 12.3 & 2.7 \\
\hline 6 Lindavista & 902 & 2.2 & 222 & 0.11 & 4.1 & 10.8 \\
\hline 7 Padierna & 741 & 1.8 & 189 & 0.10 & 3.9 & 30.1 \\
\hline 8 San Rafael & 731 & 1.8 & 177 & 0.09 & 4.1 & 9.9 \\
\hline 9 Olivar de los Padres & 251 & 0.6 & 167 & 0.09 & 1.5 & 10.9 \\
\hline 10 San Lucas & 299 & 0.7 & 201 & 0.10 & 1.5 & 11.8 \\
\hline Total de nodos aislados & 3680 & 8.8 & 712 & 0.37 & 5.2 & 30.6 \\
\hline 1 Hidalgo & 940 & 2.3 & 30 & 0.02 & 31.3 & 19.3 \\
\hline 2 Las Lomas & 915 & 2.2 & 235 & 0.12 & 3.9 & 47.8 \\
\hline 3 Jardines de Monterrey & 754 & 1.8 & 47 & 0.02 & 16.0 & 118.4 \\
\hline 4 Parques del Pedregal & 262 & 0.6 & 54 & 0.03 & 4.9 & 44.3 \\
\hline 5 Barros Sierra & 241 & 0.6 & 23 & 0.01 & 10.5 & 37.5 \\
\hline 6 Vallejo & 228 & 0.5 & 198 & 0.10 & 1.2 & 25.9 \\
\hline 7 Arcos de la Hacienda & 204 & 0.5 & 42 & 0.02 & 4.8 & 4.5 \\
\hline 8 Santa Úrsula Xitla & 136 & 0.3 & 83 & 0.04 & 1.6 & 99.8 \\
\hline
\end{tabular}

Fuente: elaboración propia a partir de INEGI (1994).

a Presentado en millones de pesos constantes a 2013.

${ }^{\text {b }}$ La intensidad de producción se expresa en millones de pesos constantes a 2013 por hectárea.

El nodo más importante se encontró en la zona central, es el de mayor tamaño con 2.3 mil hectáreas y corre a lo largo de la avenida de los Insurgentes. Este agrupamiento puede describirse como un corredor de servicios cuya ramificación principal se desarrolló a lo largo de la vía mencionada, pero que también tuvo derivaciones sobre la avenida Universidad, en la parte sur y en su sección norte a través de la avenida Chapultepec, también ha servido como conector entre la bifurcación principal y el centro histórico.

Este nodo central aportó casi $24 \%$ de la producción metropolitana y registró una intensidad de producción superior a la media de los nodos. En contraste, se observa que la cantidad de trabajadores por unidad económica es inferior a la media de los nodos, aunque superior a la media metropolitana al registrar 7.5

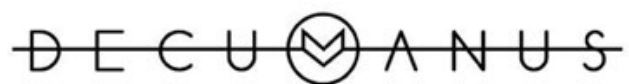

REVISTA INTERDISCIPLINARIA SOBRE ESTUDIOS URBANOS 
empleados por establecimiento. Ello muestra un predominio de microempresas, al estar en el umbral de uno a diez empleados (Cuadro 2). ${ }^{4}$

El segundo nodo de importancia fue Polanco, con una aportación discreta de casi $6 \%$, con una superficie mucho más pequeña con apenas 471 hectáreas lo que resulta en una mayor intensidad de producción al registrar \$5.1 millones por hectárea. También destaca el tamaño de las unidades económicas al promediar 11.3 empleados por establecimiento.

Resalta el nodo de Lomas Verdes, ubicado en una zona periférica al norponiente de la metrópoli, el cual se encontró en tercer lugar tanto en producción como en tamaño. La conformación de este nodo pudo relacionarse con la emblemática zona habitacional Ciudad Satélite que motivó la llegada de población de clase media durante la segunda mitad del siglo XX y la urbanización de los alrededores (Tarrés, 1999, p. 421).

Adicionalmente a los diez grandes nodos constituidos por más de una AGEB, se identifican ocho nodos aislados que se conforman por una sola AGEB con muy alto nivel de valor agregado sin áreas colindantes con producción superior a la media. Estos nodos aislados también tendieron a emplazarse en la zona poniente de la metrópoli de una manera más o menos homogénea desde el sur con Santa Úrsula Xitla, hasta el norte con Arcos de la Hacienda (Mapa 2).

En conjunto, estos nodos aislados aportaron solamente el $8.8 \%$ de la producción metropolitana. No obstante, algunos de ellos destacaron por la generación de más valor agregado que algunos nodos constituidos por más de una AGEB, al tener la más alta intensidad de producción o por albergar en promedio establecimientos más grandes. En términos generales estos nodos tuvieron una intensidad de producción mayor a los nodos con $\$ 5.2$ millones y agruparon establecimientos tres veces más grandes con 30.6 empleados por unidad económica (Cuadro 2).

Estas cualidades muestran que estos nodos aislados tuvieron una muy intensa actividad, pero por alguna razón no generaron una capacidad de aglomeración que superara los límites de los AGEB. Esto pudo vincularse con la localización periférica que tienen casi todos, a excepción de los nodos de Vallejo e Hidalgo (Mapa 2). Precisamente, este último nodo aislado fue el que mayor producción generó, siendo el AGEB con mayor valor agregado de toda la zona metropolitana. Esta área de apenas 30 hectáreas representa el 0.02\% de la superficie urbana y aportó el $2.3 \%$ de los servicios de consumo duradero. Ello derivó en la mayor intensidad de producción con \$31.3 millones por hectárea (Cuadro 2). En este nodo destacaron establecimientos educativos que pueden explicar esta concentración.

En la categoría de nodos aislados, Las Lomas ocupó el segundo lugar. Está ubicado en una exclusiva zona residencial al poniente de la Ciudad de México y seguramente sirvió de nodo local ante el alto nivel adquisitivo de la población residente. Este nodo aportó $2.2 \%$ del valor agregado en los servicios de consumo duradero y registró el tercer mayor promedio de empleados por unidad económi-

4 El INEGI (2009) clasifica las empresas de servicios de la siguiente manera: cuando tiene de uno a diez empleados es una microempresa; de 11 a 50, pequeña; de 51 a 100, mediana; y 101 o más, grande.

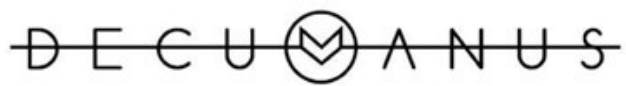

REVISTA INTERDISCIPLINARIA SOBRE ESTUDIOS URBANOS
Núm. 5. Vol. 5. Octubre 2019-Octubre 2020. Instituto de Arquitectura, Diseño y Arte.

Universidad Autónoma de Ciudad Juárez. ISSN: 2448-900X 
ca de todos los nodos. Nuevamente los colegios son los que explican la formación de este nodo.

Jardines de Monterrey fue el nodo aislado con los establecimientos más grandes al promediar 118.4 trabajadores por unidad económica. También destacó por su intensa producción al ser la segunda mayor, solo superada por el nodo Hidalgo. Este AGEB registró \$16 millones por hectárea. Nuevamente la actividad educativa fue aquello que le otorgó la importancia al nodo, se destaca la sede del Instituto Tecnológico de Estudios Superiores de Monterrey, Campus Estado de México. Este centro de educación superior y media superior superó con creces los 250 trabajadores.

La formación de estos nodos aislados pudo vincularse al emplazamiento de grandes empresas de servicios de consumo inmediato, lo que derivó en un incremento en la cantidad de personal ocupado y una intensa generación de valor agregado. Destacaron los establecimientos educativos en seis de los ocho nodos, por lo que se deduce que son la causa de esta concentración. Esto en contraste de los nodos constituidos por varios AGEB que representaron una aglomeración de diversas unidades económicas y, como es de esperarse, una mayor diversificación, donde se observa que el sector educativo es el principal generador de los núcleos.

Es claro que esta actividad económica tenía una configuración policéntrica en 1993 y concentró sus nodos en la parte centro-poniente a partir de una clara primacía del nodo central o, mejor dicho, corredor central, que se extiende a lo largo de la avenida de los Insurgentes. Ahora resta el análisis de la organización territorial 20 años después.

\section{Ligera centralización de los servicios de consumo duradero}

Los cambios en la estructura territorial de los servicios de consumo duradero que ocurrieron en 2013 no son tan grandes, en el Mapa 3 se observa que predominó nuevamente el nodo central. Aunque este corredor de servicios ya no incluyó el centro histórico, la zona de Polanco se ha integrado como una de sus ramificaciones. Asimismo, este corredor se desarrolló hacia el sur hasta Ciudad Universitaria, el campus principal de la Universidad Nacional Autónoma de México. Estos cambios en la configuración territorial del nodo han causado un mayor agrupamiento, lo que incrementó su participación en la actividad a escala metropolitana (Cuadro 3).

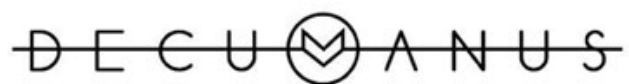

REVISTA INTERDISCIPLINARIA SOBRE ESTUDIOS URBANOS 
Mapa 3. Zona metropolitana de la Ciudad de México: distribución territorial de los servicios de consumo duradero, 2013.

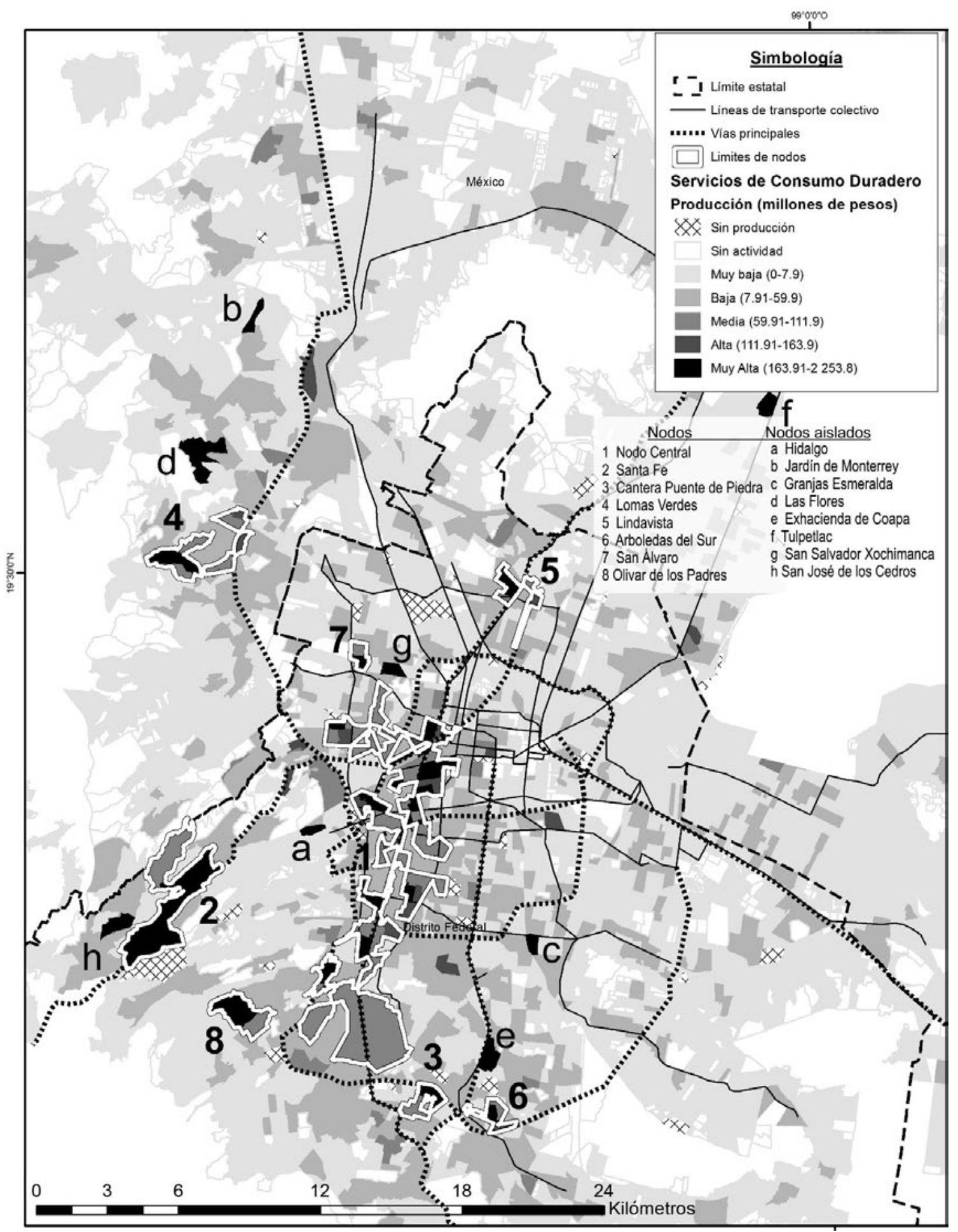

Fuente: Elaboración propia a partir de INEGI (2014).

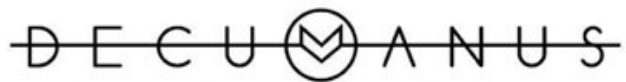

REVISTA INTERDISCIPLINARIA SOBRE ESTUDIOS URBANOS
Núm. 5. Vol. 5. Octubre 2019-Octubre 2020.

Instituto de Arquitectura, Diseño y Arte.

Universidad Autónoma de Ciudad Juárez. ISSN: 2448-900X 
Aunado a ello, la cantidad de nodos se ha reducido, al alcanzar solamente ocho respecto a los diez identificados dos décadas atrás. Su emplazamiento siguió predominando en la zona poniente de la ciudad; con excepción de los casos de Lindavista y Arboledas del Sur, localizados al norte y sur, respectivamente, estos se localizaron ligeramente al oriente (Mapa 3).

En lo que respecta a los nodos aislados, se mantuvo la misma cantidad aunque fueron reemplazados seis de ellos. Ello fue resultado de que tres nodos nuevos se localizaron en el lado centro-oriente de la zona metropolitana: Exhacienda de Coapa, en la zona sur sobre Calzada de Tlalpan; Granjas Esmeralda, ubicado en la zona centro-sur; y Tulpetlac, en el municipio de Ecatepec de Morelos. Cabe destacar que, a diferencia del resto de los agrupamientos, el emplazamiento de estos tres nodos aislados convergió con líneas de transporte colectivo; mientras que en el caso del resto, estos yacían sobre las vías principales o se encontraban insertos en zonas habitacionales que justifican la creación de dichos nodos de índole local por el alto poder adquisitivo de sus residentes (Mapa 3).

Cuadro 3. Zona metropolitana de la Ciudad de México: características generales de los agrupamientos de servicios de consumo duradero, 2013.

\begin{tabular}{|c|c|c|c|c|c|c|}
\hline \multirow[t]{2}{*}{ Agrupamientos } & \multicolumn{2}{|c|}{ Valor agregado } & \multicolumn{2}{|c|}{ Área } & \multirow{2}{*}{$\begin{array}{l}\text { Intensidad de } \\
\text { producción }\end{array}$} & \multirow{2}{*}{$\begin{array}{c}\text { Personal por } \\
\text { establecimiento }\end{array}$} \\
\hline & Hectáreas & $\%$ & Hectáreas & $\%$ & & \\
\hline \multicolumn{7}{|l|}{ Total de Actividad } \\
\hline & 45399 & 100.0 & 229706 & 100.00 & 0.20 & 5 \\
\hline Nodo central & 11206 & 24.7 & 2962 & 1.29 & 3.78 & 13 \\
\hline Santa Fe & 2340 & 5.2 & 844 & 0.37 & 2.77 & 23 \\
\hline Cantera Puente de Piedra & 1626 & 3.6 & 143 & 0.06 & 11.37 & 7 \\
\hline Lomas Verdes & 1159 & 2.6 & 421 & 0.18 & 2.75 & 23 \\
\hline Lindavista & 667 & 1.5 & 176 & 0.08 & 3.79 & 13 \\
\hline Arboledas del Sur & 594 & 1.3 & 119 & 0.05 & 4.98 & 26 \\
\hline San Álvaro & 324 & 0.7 & 71 & 0.03 & 4.59 & 19 \\
\hline Olivar de los Padres & 296 & 0.7 & 256 & 0.11 & 1.16 & 41 \\
\hline Hidalgo & 2254 & 5.0 & 31 & 0.01 & 71.58 & 31 \\
\hline Jardines de Monterrey & 512 & 1.1 & 45 & 0.02 & 11.40 & 41 \\
\hline Granjas Esmeralda & 366 & 0.8 & 34 & 0.01 & 10.75 & 18 \\
\hline Las Flores & 323 & 0.7 & 202 & 0.09 & 1.59 & 127 \\
\hline Ex Hacienda de Coapa & 290 & 0.6 & 75 & 0.03 & 3.87 & 94 \\
\hline Tulpetlac & 281 & 0.6 & 53 & 0.02 & 5.27 & 34 \\
\hline San Salvador Xochimanca & 260 & 0.6 & 44 & 0.02 & 5.84 & 82 \\
\hline San José de los Cedros & 198 & 0.4 & 79 & 0.03 & 2.50 & 12 \\
\hline
\end{tabular}

Fuente: Elaboración propia a partir de INEGI (2014).

${ }^{a}$ La intensidad de producción se expresa en millones de pesos por hectárea.

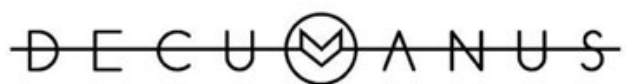

REVISTA INTERDISCIPLINARIA SOBRE ESTUDIOS URBANOS 
Estos ligeros cambios muestran un discreto ajuste de la estructuración espacial de los servicios de consumo duradero hacia una mayor participación del nodo central y de los nodos aislados (Cuadro 3). Los nodos perdieron participación en la actividad al aportar $40 \%$ de la producción metropolitana en una superficie menor a la registrada en 1993, 2.17\% de la extensión urbana.

Como ya se había mencionado, el nodo central incrementó su participación en la generación del valor agregado al aportar $24.7 \%$ del total metropolitano, en una superficie ligeramente mayor que representa $1.29 \%$ del total del área urbanizada. Bajo la misma tendencia general, el tamaño de los establecimientos creció, al promediar 13 empleados por unidad económica. Este incremento generalizado representó una contratendencia hacia la "changarrización", que ha caracterizado gran parte de la economía mexicana (Campos y Berra, 2007, p. 159), para dar paso a una predominancia de nodos de pequeñas empresas sobre los de microempresas.

El segundo nodo fue resultado de un esfuerzo por parte del gobierno para construir un centro financiero y de servicios en la zona periférica de la metrópoli. A partir de la última década del siglo XX, inició la planificación del megaproyecto urbano que alcanzó su estable crecimiento al comienzo del nuevo siglo (Díaz, 2018). Este nodo se posiciona como el segundo nodo más importante de la ciudad al aportar 5.2\% del valor agregado de los servicios. De igual forma, fue el segundo nodo más extenso con una superficie que representa $0.37 \%$ del área urbana.

Es claro que la importancia de los nodos en cuanto a generación de valor agregado de servicios de consumo duradero ha disminuido, pese al incremento de la producción del nodo central. Ello se vinculó con una mayor participación de los nodos aislados que se relocalizan hacia nuevos territorios que anteriormente no ameritaban la actual concentración económica.

De tal manera que los nodos aislados aportaron casi $10 \%$ de la producción metropolitana pese a su reducción de extensión al representar solamente $0.25 \%$ de la superficie urbana, lo que derivó en un incremento en su intensidad de producción, registrando casi \$8 millones por hectárea. La tendencia general, también el tamaño de los establecimientos en estos nodos se incrementó a 36 empleados por unidad económica, en promedio.

Nuevamente el nodo de Hidalgo fue el que generó más valor agregado, ya que aportó la mitad de la producción de todos los nodos aislados. Esta clara primacía se observa al concentrar $5 \%$ de la producción metropolitana y registrar la más alta intensidad de producción de toda la zona metropolitana al alcanzar \$71.58 millones por hectárea. Este AGEB, por sí solo, se posicionó como la tercera agrupación de mayor producción, sólo por detrás del Nodo Central y Santa Fe.

Es claro que la distribución de los servicios de consumo duradero fue bastante estable y el policentrismo fue el patrón principal, con una ligera centralización de la producción en favor del nodo central y una tenue segmentación en favor de los nodos aislados. No obstante, la siguiente sección muestra con mayor detalle las transformaciones en la actividad económica a escala metropolitana.

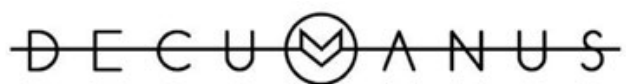

REVISTA INTERDISCIPLINARIA SOBRE ESTUDIOS URBANOS
Núm. 5. Vol. 5. Octubre 2019-Octubre 2020. Instituto de Arquitectura, Diseño y Arte.

Universidad Autónoma de Ciudad Juárez. ISSN: 2448-900X 


\section{Evolución de los servicios de consumo duradero}

La concentración de este sector económico ha mostrado un proceso dinámico de emplazamiento como resultado de múltiples factores vinculados con la accesibilidad y la distribución heterogénea de la población. Esta sección tiene como objetivo analizar los cambios territoriales que tuvieron los servicios de consumo duradero en un plazo de 20 años y asi valorar una tendencia evolutiva.

Cabe recordar que este análisis se enfoca en la revisión de los cambios, en cuanto a participación de la actividad económica, causados por modificaciones intrínsecas a la unidad espacial. Es decir, se desvinculan los cambios por razones del crecimiento propio de toda la actividad económica y el cambio sectorial a través del modelo de "cambio y participación". Ello permite exponer las transformaciones asociadas con las cualidades territoriales de cada AGEB.

\begin{tabular}{lrrrr}
$\begin{array}{c}\text { Cuadro 4. Zona metropolitana de la Ciudad de México: cambios por factores } \\
\text { locales por AGEB de los servicios de consumo duradero, 1993-2013. }\end{array}$ \\
$\begin{array}{l}\text { Nivel de cambio } \\
\text { Cantidad de AGEB }\end{array}$ & $\%$ & Área (ha) & $\%$ \\
\hline Total & 5694 & 100.0 & 229706 & 100.0 \\
& & & & \\
Decremento Alto & 98 & 1.7 & 4503 & 2.0 \\
Decremento Medio & 1427 & 25.1 & 46104 & 20.1 \\
Sin Cambio & 1564 & 27.5 & 56936 & 24.8 \\
Incremento Medio & 2529 & 44.4 & 117114 & 51.0 \\
Incremento Alto & 76 & 1.3 & 5049 & 2.2 \\
\hline
\end{tabular}

Fuente: Elaboración propia a partir de INEGI (1994; 2014).

Se puede observar que $44.4 \%$ de las AGEB tuvieron un incremento medio de su actividad económica al representar $51 \%$ de la superficie metropolitana. En segunda instancia se observa que casi $28 \%$ de las áreas no tuvieron cambios en cuanto a su producción por factores locales, lo que representa casi un cuarto de la extensión urbana. En tercer lugar se encuentran las áreas con un decremento moderado de la actividad al representar un cuarto de las AGEB urbanas y $20 \%$ de la superficie de la urbe. Por último, los altos incrementos y decrementos contabilizan de manera conjunta sólo el 3\% de las AGEB (Cuadro 4). No obstante, su localización se encuentra mayoritariamente focalizada en la zona poniente y está vinculada con el emplazamiento de los nodos.

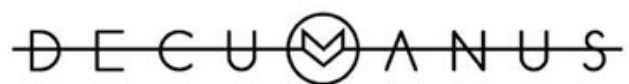

REVISTA INTERDISCIPLINARIA SOBRE ESTUDIOS URBANOS 
Mapa 4. Zona metropolitana de la Ciudad de México: cambios en la distribución de los servicios de consumo duradero por razones locales, 1993-2013.

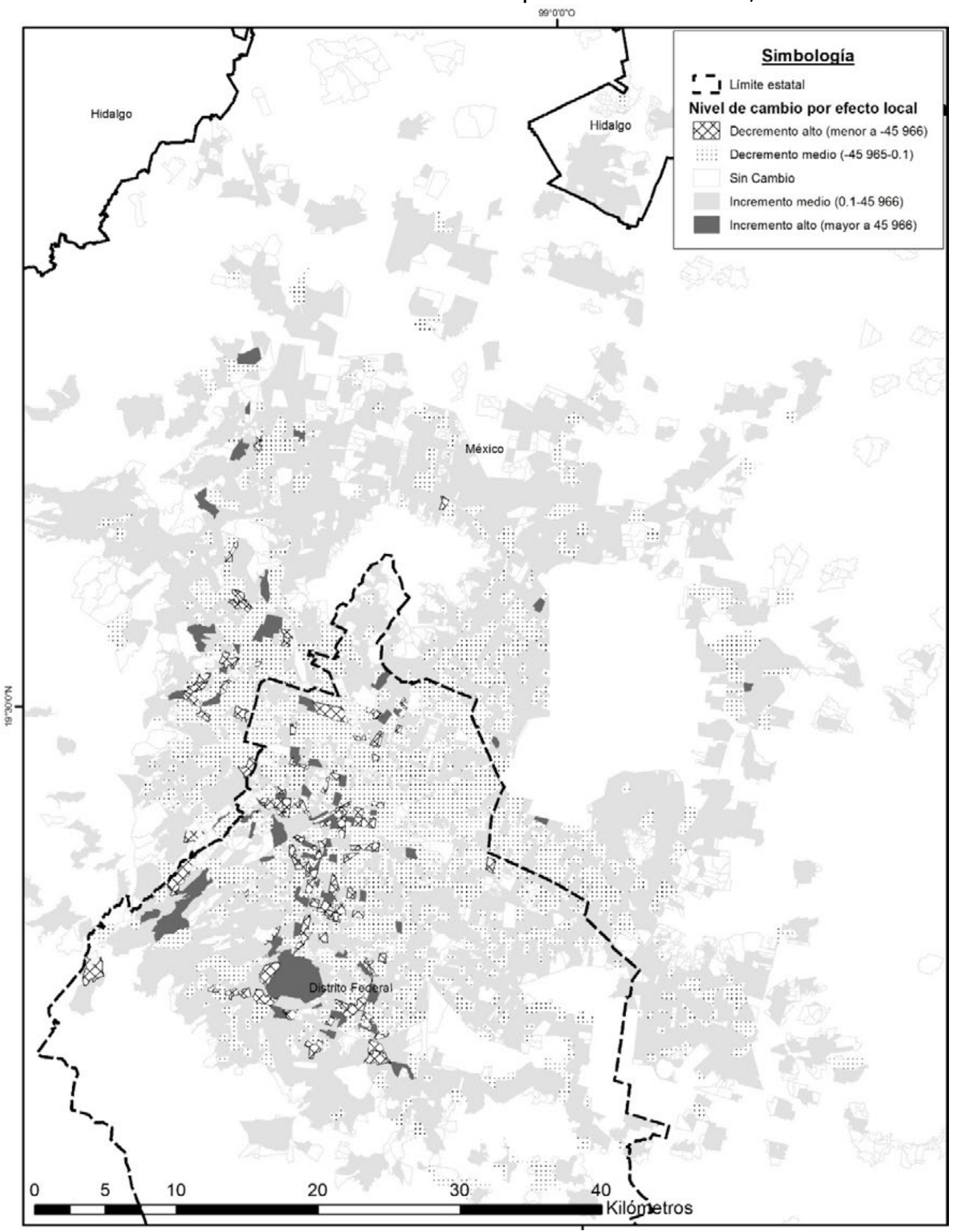

Fuente: Elaboración propia a partir de INEGI (1994; 2014).

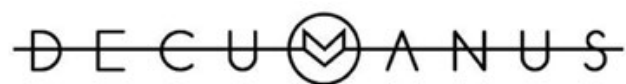

REVISTA INTERDISCIPLINARIA SOBRE ESTUDIOS URBANOS 
En términos generales, se observa un incremento en la zona periférica, que contrasta con el decremento en la zona central. Ello aparenta un discreto proceso de descentralización de la actividad a escala metropolitana, sobre todo de las áreas donde la actividad económica es muy baja (Mapa 4). Esta tendencia, podría contrarrestar la tendencia hacia la concentración, no obstante, la producción de estas zonas es tan baja que no impacta en la configuración metropolitana.

De manera más específica, se puede observar que tanto en la periferia como en la zona central se identifican numerosas áreas con decremento o incremento medio (Mapa 4). Ello muestra una predominancia de cambios territoriales de la actividad a una escala local, que a escala metropolitana son muy sutiles como resultado de la poca actividad que se realiza en estas zonas. Los cambios más contrastantes se vinculan con la configuración de los nodos previamente identificados, tanto en 1993 como en 2013. Es decir, los altos incrementos y altos decrementos se emplazan en la zona poniente con contadas excepciones que se localizan en la zona oriente (Mapa 4).

La zona más dinámica de la metrópoli es precisamente el nodo central, que corre a lo largo de la avenida de los Insurgentes. En dicha zona se identifican numerosas áreas con importantes incrementos y decrementos de los servicios de consumo duradero, lo que muestra una alta volatilidad de la actividad en cuanto a su localización a escala local. Este fenómeno es similar al del resto de la zona metropolitana, pero también es más contrastante. Estos cambios muestran la trascendencia que tiene la avenida como generador del corredor de servicios, pero su morfología está sometida a los intensos cambios de la actividad económica.

Algo similar ocurre en el otrora nodo de Polanco que debido a los grandes decrementos de actividad, pierde importancia y sus remanentes se integran al nodo central, favorecidos por otra avenida emblemática, Paseo de la Reforma. De igual forma, los nodos de Santa Úrsula, Lindavista y Lomas Verdes tienen en su interior un AGEB con altos incrementos y decrementos, lo que lleva a un cambio en sus límites o, en el caso del primero, su segmentación en dos nodos de menor tamaño: Arboledas del Sur y Cantera Puente de Piedra.

Esta evolución muestra que la localización de los nodos responde a condiciones territoriales que favorecen la concentración de la actividad económica en dicho lugar gracias a las ventajas de conectividad que ofrecen las vías de comunicación. No obstante, el detalle de su morfología está condicionado a otros factores que pueden estar vinculados con el entorno local. Es decir, la buena conectividad metropolitana no necesariamente es garantía de un establecimiento exitoso, si se habla a escala local.

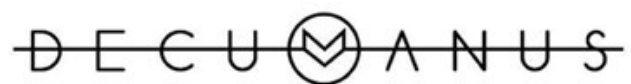

REVISTA INTERDISCIPLINARIA SOBRE ESTUDIOS URBANOS 
Cuadro 5. Zona metropolitana de la Ciudad de México: nivel de cambio por razones locales según nivel de producción en 2013 de los servicios de consumo duradero, 1993-2013

\begin{tabular}{lrrrrrrrrrrr}
$\begin{array}{c}\text { Nivel de } \\
\text { producción }\end{array}$ & $\begin{array}{c}\text { Decremen- } \\
\text { to Alto }\end{array}$ & $\%$ & $\begin{array}{c}\text { Decremento } \\
\text { Medio }\end{array}$ & $\%$ & $\begin{array}{c}\text { Sin } \\
\text { Cambio }\end{array}$ & $\%$ & $\begin{array}{c}\text { Incremento } \\
\text { Medio }\end{array}$ & \multicolumn{2}{c}{$\begin{array}{c}\text { Incremento } \\
\text { Alto }\end{array}$} & $\%$ \\
\hline Total & 98 & 100.0 & 1427 & 100.0 & 1564 & 100.0 & 2529 & 100.0 & 76 & 100.0 \\
Sin produc- & & & & & & & & & & \\
ción & 9 & 9.2 & 28 & 2.0 & 0 & 0.0 & 0 & 0.0 & 0 & 0.0 \\
Sin actividad & 2 & 2.0 & 129 & 9.0 & 1561 & 99.8 & 2 & 0.1 & 0 & 0.0 \\
Muy Baja & 15 & 15.3 & 1022 & 71.6 & 3 & 0.2 & 2060 & 81.5 & 0 & 0.0 \\
Baja & 45 & 45.9 & 227 & 15.9 & 0 & 0.0 & 440 & 17.4 & 15 & 19.7 \\
Media & 17 & 17.3 & 16 & 1.1 & 0 & 0.0 & 20 & 0.8 & 24 & 31.6 \\
Alta & 5 & 5.1 & 2 & 0.1 & 0 & 0.0 & 6 & 0.2 & 9 & 11.8 \\
Muy Alta & 5 & 5.1 & 3 & 0.2 & 0 & 0.0 & 1 & 0.0 & 28 & 36.8 \\
\hline
\end{tabular}

Fuente: Elaboración propia a partir de INEGI (1994; 2014).

Los cambios en cuanto a la producción influyeron en los microcambios que se observan en el Mapa 4. La gran mayoría de las áreas con producción muy baja son las más cambiantes al registrar incrementos y decrementos medios (Cuadro 5). Como se pudo observar, este fenómeno se manifiesta en casi toda el área metropolitana.

Destaca el caso de las áreas sin cambio, pues $99.8 \%$ no registraron actividad de este tipo de servicios. Lo anterior se debe a que estas zonas están consolidadas con otras actividades urbanas, aunque muchas otras, al encontrarse en la periferia metropolitana, se explican bajo una condición de mercado insuficiente. Es decir, estas zonas urbanas de baja densidad y bajo poder adquisitivo no han tenido la capacidad de atraer servicios de consumo duradero.

Finalmente, la mayoría de los altos decrementos terminaron con una producción baja que, como ya se observó previamente, se localizaba en las zonas de los nodos. Bajo esa misma lógica, $36.8 \%$ de los altos incrementos registraron una producción muy alta, seguidos de $31.6 \%$ de áreas que alcanzaron una producción media (Cuadro 5). Nuevamente, la mayoría de estas áreas con muy alto incremento se emplazan en la zona poniente, donde prevalecen los nodos metropolitanos.

Estas cifras refuerzan el argumento previamente planteado: los cambios en la actividad se expresan en todas las zonas de la urbe, pero con una mayor intensidad en las zonas de los nodos. Sin lugar a dudas, la estructura territorial de los servicios de consumo duradero es relativamente estable a escala metropolitana, pero con cambios a una microescala que denota una volatilidad de las empresas de este sector.

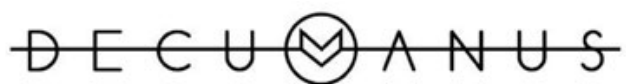

REVISTA INTERDISCIPLINARIA SOBRE ESTUDIOS URBANOS 


\section{Conclusiones: evolución multiescalar de la distribución de los servicios de consumo duradero}

La organización microespacial de los servicios de consumo duradero ha evolucionado de una manera bi-escalar. Por un lado, se identifica una lenta transformación del patrón policéntrico hacia la concentración a una escala metropolitana, mientras que, por otro lado, existió una reconfiguración de la actividad que modificó la morfología de los nodos y propició la aparición de nuevos y la desaparición de otros.

En lo que se refiere a la escala metropolitana, se observa un policentrismo con una clara predominancia de un corredor urbano que nació en el centro histórico de la urbe y que se desarrolló hacia el sur en la avenida medular de la metrópoli, la avenida de los Insurgentes. Este nodo ofreció una variedad de servicios, pues abarcó desde zonas exclusivas, como la zona de Paseo de la Reforma, hasta otras con servicios más accesibles, como la colonia Obrera. No obstante, la morfología de este corredor se fue transformando, el centro histórico perdió trascendencia a tal grado de dejar de formar parte del corredor. Este proceso concuerda con la interesante afirmación de Dematteis y Governa (2001) sobre la dilución del centro. Asimismo, la ramificación del corredor hacia la colonia Obrera, que ofreció servicios más accesibles para la población de la zona oriente de la metrópoli, perdió fuerza en su actividad, por lo que dejó de formar parte del nodo. Esto muestra una tendencia de desatención del nodo central a la población con menor poder adquisitivo de la zona oriente. Esta tendencia refuerza el proceso de fragmentación urbana que describe Burgess (2011).

De manera secundaria, se constituyó una serie de nodos altamente generadores de servicios especializados, pero con una extensión muy reducida que refuerza la visión de Veltz (1999) sobre la creciente microdiferenciación de la actividad urbana frente a la aparente disolución de macrodiferencias. En el periodo de estudio, algunos se transformaron en cuanto a su morfología y otros se relocalizaron, pero bajo una mayor predominancia de su emplazamiento en la zona poniente de la urbe, como resultado del mayor mercado que representa este segmento de la población.

Destaca entre estos nodos el de Santa Fe, el cual fue concebido para la construcción de un distrito con vivienda, empleo y servicios. Este megaproyecto fortalece el postulado de Kozak (2011) sobre los procesos de fragmentación social que generan espacios de autosegregación, aunque ha sido el único caso en toda la metrópoli. Este fenómeno concuerda con la afirmación de Gaschet (2002) sobre la hipótesis de independencia suburbana. No obstante, para el caso de la Ciudad de México, este proceso se vincula con la fragmentación urbana donde la organización intraurbana de este tipo de servicios se construye de una forma dual.

Esta concentración fue posible por la disponibilidad que tiene la población consumidora para desplazarse con el fin de recibir este tipo de servicio. No obstante, se observa un franco acercamiento de estos servicios hacia la zona con

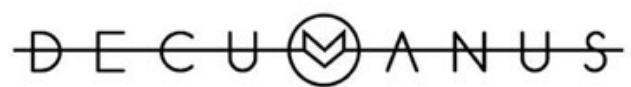

REVISTA INTERDISCIPLINARIA SOBRE ESTUDIOS URBANOS 
población de mayor poder adquisitivo mediante la formación de nodos de trascendencia regional al pie de vialidades primarias.

La zona oriente mostró un patrón muy disperso de la actividad de servicios de consumo duradero que posiblemente respondió a la necesidad del oferente de acercarse a una población cuyo ingreso no le facilita gastar en largos viajes tal y como lo argumentan Davies (1972) y Potter (1980, p. 209). Es de esperarse que este tipo de servicios sean básicos como la educación media superior o algunos centros educativos profesionalizantes con un enfoque técnico, y servicios de salud de primer nivel y algunos servicios modestos de hospitalización. También en esta zona predominaron los centros de reparación, pues la mayoría de la población, al no tener la capacidad de renovación constante de sus bienes de consumo, prefiere acudir a un taller de reparación. Estos centros son establecimientos pequeños que se distribuyeron de manera dispersa en toda la zona.

Del lado poniente de la metrópoli, la predominancia de los nodos respondió mayoritariamente a la concentración de servicios educativos, especialmente de educación superior. Estos centros escolares constituyeron los núcleos de los nodos con la capacidad de atraer servicios complementarios. La cualidad de estos nodos altamente especializados se ajusta a la propuesta de Berry (1971), aunque el autor hace más énfasis en los servicios de salud. Se identificaron también algunos nodos aislados que se pueden explicar por ser centros que ofrecen educación preescolar hasta media superior y tienen un alcance más local que su área de influencia, la cual no traspasó el AGEB.

Si bien es posible identificar una ligera expansión de la actividad económica en la periferia metropolitana como resultado del desarrollo de la urbe, esta dispersión no tuvo la suficiente intensidad de producción como para abatir la tendencia hacia la concentración. No obstante, deja entrever la importancia que van adquiriendo los nuevos mercados en la periferia extendida, donde nuevamente la zona poniente generó una mayor atracción de este tipo de servicio.

El otro nivel de análisis donde se observa una mayor dinámica en la distribución de los servicios de consumo duradero es la escala local. Al analizar a mayor detalle la organización territorial de la actividad, destacaron cambios tenues en toda la zona metropolitana y otros más contrastantes en la zona poniente, donde se concentró la mayor actividad.

Aunque a escala metropolitana predominan los decrementos medios en la zona central e incrementos medios en la periferia, se identificaron ambos procesos en toda la zona metropolitana. Este fenómeno tuvo implicaciones en la dinámica del servicio que tiene una atención más local, como pueden ser los servicios de educación básica, clínicas de primer contacto y centros de reparación de bienes. En la zona poniente de la ciudad destacó una mezcla de AGEB con altos incrementos y decrementos. Interesante es observar que casi todos los nodos de los dos periodos de análisis se vieron afectados por estos cambios drásticos en la generación de valor agregado de la actividad económica.

Esta micro-dinámica tiene efectos en la formación y morfología de los nodos. No llega a transformar el patrón metropolitano, pero los incrementos y decre-

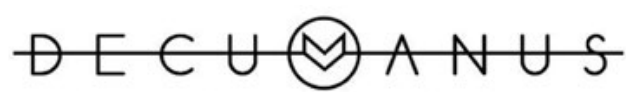

REVISTA INTERDISCIPLINARIA SOBRE ESTUDIOS URBANOS
Núm. 5. Vol. 5. Octubre 2019-Octubre 2020. Instituto de Arquitectura, Diseño y Arte.

Universidad Autónoma de Ciudad Juárez. ISSN: 2448-900X 
mentos en el interior de los nodos son tan intensos que demuestran la volatilidad que pueden tener los establecimientos de este tipo de servicios, sin importar si se encuentran integrados a una aglomeración que se beneficia de la infraestructura vial o del agrupamiento con otros servicios del mismo tipo. Es decir, se puede destacar el papel que tienen las vías de comunicación para favorecer la formación de nodos de servicios de consumo duradero. Sin embargo, el éxito de una zona, por más que se encuentre inmersa en un nodo consolidado y que prevalece con el paso de las décadas, no se encuentra garantizado. Al contrario, es aún más propensa a fuertes decrementos en comparación de los establecimientos emplazados fuera de los nodos. Incluso se observa que núcleos de muy alta actividad de servicios se ven afectados por otros factores locales que requieren de un estudio más detallado a una escala local.

\section{Gráfica 1. Propuesta sintética de la distribución intraurbana de los servicios de consumo duradero.}

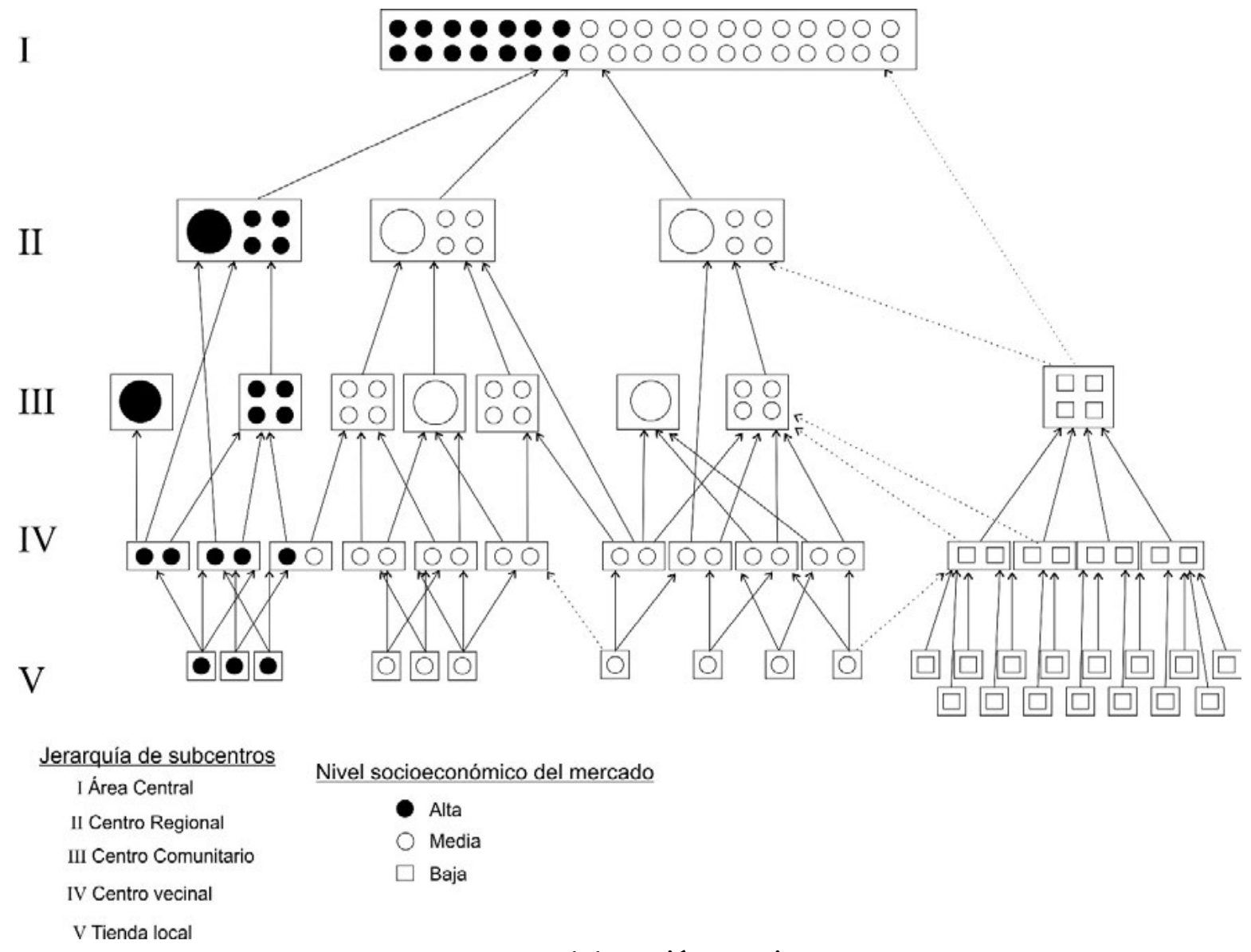

Fuente: Elaboración propia.

A manera de síntesis, se presenta una propuesta de organización microespacial de los servicios de consumo duradero, la cual busca describir las cualidades más

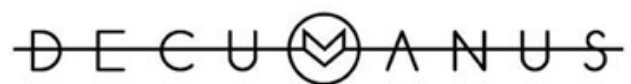

REVISTA INTERDISCIPLINARIA SOBRE ESTUDIOS URBANOS 
importantes en cuanto a la jerarquía de las agrupaciones, tamaño de los establecimientos, población ocupada, nivel socioeconómico que atiende, relaciones que se construyen por los consumidores y, para este tipo de actividad en particular, la formación de un corredor como nodo central. Se retoma la propuesta de Davies (1972) y se realizan una serie de adecuaciones en función de la evidencia empírica que ofrece el caso de estudio.

Existen algunos elementos que se mantienen de la propuesta original, donde se reconoce una clara jerarquización entre los diferentes nodos urbanos en función del grado de especialización de los servicios. También se identifica una diferenciación entre los nodos que se enfocan a atender a un segmento socioeconómico específico de la población.

Los cambios indican una diferencia en la cantidad de oferta de servicios del rango $\mathrm{V}$ (tiendas locales) en función del nivel socioeconómico de la población, siendo mucho más abundante para el nivel bajo dada su poca disposición a realizar largos viajes para satisfacer sus necesidades de servicios. En contraste, en la zona de oferta de alto y medio nivel socioeconómico, escasean los establecimientos de esta jerarquía en favor de los nodos.

La predominancia de agrupamientos de baja jerarquía que atienden a una población de bajo nivel socioeconómico se conjuga con la ausencia de nodos de gran alcance bajo el mismo argumento de poca disposición a realizar viajes largos por la población de bajo nivel socioeconómico. Ello deriva en una ausencia de nodos regionales y pocos centros comunitarios especializados en servicios de consumo duradero. Ello obliga a la población de bajo nivel socioeconómico a realizar largos traslados para satisfacer sus necesidades de servicios altamente especializados ofrecidos en otras zonas de la urbe, como pueden ser la educación de posgrado o servicios de salud altamente especializados.

En relación con la oferta focalizada a la población con un nivel socioeconómico alto y medio, se identifican los nodos de servicios en todos sus niveles. Al interior de los nodos de rango III y IV, que se manifiestan como los nodos y los nodos aislados, se pueden encontrar centros educativos y de salud de gran envergadura, resultado del proceso histórico de centralización general del capital que representan los núcleos de muy alta actividad. Además, es importante destacar los nodos no jerarquizados de educación generados por los nodos aislados que formalmente no representan un nivel superior de oferta, sino más bien una especializada.

Por último, se examinó el nodo central, que formalmente constituye un corredor de servicios que manifiesta la trascendencia que tiene las vías de comunicación centrales de las urbes. Este corredor ofrece, a lo largo de su trayectoria, variedad de servicios accesibles a casi toda la población. Este nodo central tiende hacia los principales mercados, aunque pierde posicionamiento en el segmento de la población con un nivel socioeconómico bajo. De tal forma que los establecimientos, que en su mayoría son de tamaño pequeño, se enfocan en atender a la población de nivel socioeconómico medio y alto.

Sin duda alguna, este estudio ofrece un panorama general muy interesante sobre la dinámica microespacial de la distribución de los servicios, la cual mo-

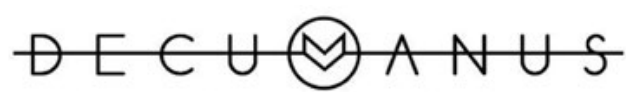

REVISTA INTERDISCIPLINARIA SOBRE ESTUDIOS URBANOS 
difica ligeramente la estructuración metropolitana. No obstante, abre una serie de interrogantes sobre el detalle de esos procesos microespaciales y los factores que motivan la dinámica de la actividad ante una lógica metropolitana de relativa estabilidad a favor de los nodos cercanos a las vías de comunicación.

\section{Referencias}

Aguilar, A. y P. Mateos (2011). Diferenciación sociodemográfica del espacio urbano de la Ciudad de México. EURE, 37(110), 5-30.

Arellano, B. y J. Roca (2010). El urban sprawl, ¿Un fenómeno de alcance planetario?: los ejemplos de México y España. Arquitectura, Ciudad y Entorno, IV(12), 115-147.

Berry, B. (1971). Internal structure of the city. En L. Bourne (ed.), General features of urban commercial structure (pp. 361-367). Toronto: Oxford University.

Borsdorf, A. (2003). Cómo modelar el desarrollo y la dinámica de la ciudad latinoamericana. EURE, 29(86), 37-49.

Burgess, R. (2011). Determinismo tecnológico y fragmentación urbana: un análisis crítico. En E. Pradilla Cobos (ed.), Ciudades compactas, dispersas, fragmentadas (pp. 63-98). Ciudad de México: UAM/Porrúa.

Campos, G. y Y. Berra (2007). Las políticas de empleo en los "gobiernos del cambio" en México. Expresión Económica, (18-19),151-160

Consejo Nacional de Población (1994). Evolución de las ciudades de México, 1900-1990. Ciudad de México: Conapo.

Dematteis, G. y F. Governa (2001). Urban form and governance: the new multi-centred urban pattern. En H. Andersson, G. Jorgensen, D. Joye y W. Ostendorf (eds.), Change and stability in urban Europe: form, quality and governance (pp. 27-45). Aldershot: Ashgate.

Daniels, P. (1985). Service industries: a geographical appraisal. Londres: Methuen.

Díaz, M. de J. (2018). Santa Fe, su origen. En R. González y R. Martínez (coords.), Santa Fe, una mirada hacia el futuro: desarrollo urbano, gobernanza y administración pública (pp. 77-108). Ciudad de México: Instituto Nacional de Administración Pública.

García, C. (2016). Teorías e historia de la ciudad contemporánea. Barcelona: Gustavo Gili.

Garza, G. (1985). El proceso de industrialización en la Ciudad de México, 1821-1970. Ciudad de México: El Colegio de México.

Garza, G. (2008). Macroeconomía del sector servicios en la Ciudad de México. Ciudad de México: El Colegio de México.

Gaschet, F. (2002). The new intra-urban dynamics: suburbanisation and functional specialisation in French cities. Papers in Regional Science, (81), 63-81.

Gormsen, E. (1981). Die Städte im spanischen Amerika: ein zeit-räumlichen Entwicklungsmodell der letzten hundert Jahre. Erdkunde, 35(4), 290-303.

Grajales, G. (2006). Microestructuración del sector servicios de la Ciudad de México. En G. Garza (ed.), La organización espacial del sector servicios en México (pp. 457-500). Ciudad de México: El Colegio de México.

Instituto Nacional de Estadística y Geografía (1994). Censo económico 1994. Aguascalientes: INEGI.

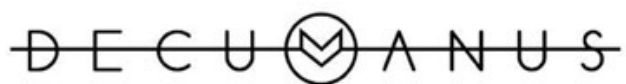

REVISTA INTERDISCIPLINARIA SOBRE ESTUDIOS URBANOS 
Instituto Nacional de Estadística y Geografía (1999). Metodología: censos económicos 1999. Aguascalientes: INEGI.

Instituto Nacional de Estadística y Geografía (2004). Metodología para las actividades del sector industrias manufactureras. Aguascalientes: INEGI.

Instituto Nacional de Estadística y Geografía (2009). Micro, pequeña, mediana y gran empresa. Aguascalientes: INEGI.

Instituto Nacional de Estadística y Geografía (2014). Censo económico 2014. Aguascalientes: INEGI.

Isard, W. (1960). Methods of regional analysis. Massachusetts: MIT.

Janoschka, M. (2002). El nuevo modelo de la ciudad latinoamericana: fragmentación y privatización. Eure, 28(85), 11-29.

Kohsaka, H. (1986). The location process of central place system within a circular city. Economic Geography, 62(3), 254-266.

Kozak, D. (2011). Fragmentación urbana y neoliberalismo global. En E. Pradilla Cobos (ed.), Ciudades compactas, dispersas, fragmentadas (pp. 13-62). Ciudad de México: UAM/Porrúa.

Lynch, K. (1981). A theory of good city form. Massachusetts: MIT.

Méndez, R. (2001). Transformaciones económicas y reorganización territorial en la región metropolitana de Madrid. Eure, XXVII(80), 141-161.

Potter, R. (1980). Spatial and structural variations in the quality characteristics of intra-urban retailing centres. Transactions of the Institute of British Geographers, 5(2), 207-228.

Ramajo, J. y Márquez, M. Á. (2008). Componentes espaciales en el modelo Shift-Share. Una aplicación al caso de las regiones peninsulares españolas, Estadística Española, 50(168), 247-272.

Secretaría de Desarrollo Social, Consejo Nacional de Población e Instituto Nacional de Estadística y Geografía (2012). Delimitación de las zonas metropolitanas de México 2010. Ciudad de México: Sedesol/Conapo/INEGI.

Tarrés, M. L. (1999). Vida en familia: prácticas privadas y discursos públicos entre las clases medias de Ciudad Satélite. Estudios Sociológicos, 17(50), 419-439.

Trullen, J. y Boix, R. (2003). Barcelona, metrópolis policéntrica en red [Documento de trabajo]. Departament d'Economia Aplicada, Universitat Autònoma de Barcelona. Recuperado dehttp://www.ecap.uab.es/RePEc/doc/wpdea0303.pdf

Veltz, P. (1999). Mundialización, ciudades y territorios: la economía de archipiélago. Barcelona: Ariel.

Yang, W. (1990). The context of Beijing's commercial network -an empirical study on the central place model. Geojournal, 21(1-2), 49-55.

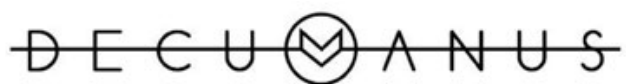

REVISTA INTERDISCIPLINARIA SOBRE ESTUDIOS URBANOS
Núm. 5. Vol. 5. Octubre 2019-Octubre 2020. Instituto de Arquitectura, Diseño y Arte.

Universidad Autónoma de Ciudad Juárez. ISSN: 2448-900X 